\title{
- A posse de animais e a responsabilidade civil
}

\section{- Animal ownership and civil responsibility}

Francheschini e Miranda Advogados Av. Brigadeiro Faria Lima $n^{0} 1461$ $13^{\circ}$ and. - Torre Sul - São Paulo e-mail:advfm@uol.com.br

\section{NeucinaC. de Oliveira Tropardi-OAB/SP n ${ }^{0} 151.048$}

Advogada - Doutoranda em Direito Civil da Faculdade de Direito - LSP

\section{RESUMO}

O objetivo desse artigo é o de analisar a responsabilidade civil de proprietários de animais pelos danos que podem causar. São considerados os aspectos gerais das leis de responsabilidade civil no Brasil, e analisa-se detalhadamente o artigo $\mathrm{n}^{\circ} 1.527$ do Código Civil, que estabelece a responsabilidade de proprietários a outros que o animal tenha causado danos. São discutidas as ações judiciais que podem ser impetradas e as indenizações, além de aspectos penais dos casos.

Unitermos: posse de animais, responsabilidade civil, danos causados por animais.

\section{I - Introdução}

O presente trabalho tem por escopo analisar a responsabilidade civil do dono e do detentor de animal pelos danos causados por este. Assim sendo num primeiro momento, serão analisados os aspectos gerais da responsabilidade civil no direito pátrio. A seguir, será feito um exame detalhado do artigo ${ }^{\circ} 1.527$ do Código Civil, que estabelece a responsabilidade civil do dono, ou do detentor, pelos danos causados por animais. Em seguida, serão tecidas breves considerações acerca da ação judicial que pode ser intentada pela vítima de um dano provocado por um animal, bem como sobre as verbas indenizatórias que podem ser pleiteadas pela vítima. Por fim será rapidamente abordado o aspecto penal referente aos danos provocados por animais.

\section{II - Breves considerações acerca da responsabilidade civil no direito brasileiro}

De um modo geral, a responsabilidade civil pode ser entendida como a obrigação imposta a uma pessoa no sentido de que a mesma repare o prejuízo que causou a outra pessoa, seja por fato próprio, seja por fato de pessoas ou coisas que dela dependam. Ou seja, todo aquele que provoca prejuízo a outrem, fica obrigado ressarcir a vítima. Esse é um dos princípios basilares de nosso direito civil, expresso no artigo $\mathrm{n}^{\mathrm{o}} 159$ do Código Civil, que estabelece que "Aquele que, por ação ou omissão voluntária, negligência, ou imprudência, violar direito, ou causar prejuízo a outrem, fica obrigado a reparar o dano".

Nesse passo é importante salientar que se pode falar em responsabilidade subjetiva e responsabilidade 
TROPARDI, N. C. O. A posse de animais e a responsabilidade civil. / Animal ownership and civil responsibility. Rev. educ. contin. CRMV-SP / Continuous Education Journal CRMV-SP, São Paulo, volume 2, fascículo 3, p. 077 - 083, 1999.

objetiva. Não se trata, na verdade, de duas espécies distintas de responsabilidade, mas de formas diferentes de encarar a obrigação de reparar o dano.

A responsabilidade será subjetiva quando se basear na culpa do agente causador do dano. Neste caso, a responsabilidade do agente somente será configurada quando se demonstrar que o agente agiu culposa ou dolosamente. Em Direito Civil, a culpa pode ser caracterizada pela negligência, imprudência ou imperícia do agente causador do dano. Aqui não há intenção deliberada do agente em prejudicar a vítima. Como exemplo de atuação culposa podemos citar um acidente de trânsito em que o condutor do veículo viola o limite de velocidade permitido e acaba por atropelar um pedestre. Nesta hipótese, o condutor do veículo não teve a intenção deliberada de prejudicar a vítima, apenas agiu imprudentemente, na medida em que violou o limite de velocidade permitido.

Por outro lado, quando se trata em dolo, fala-se justamente na intenção deliberada de prejudicar a vítima. Ora, se uma pessoa dispara um revólver num inimigo, é evidente seu propósito de atingir a vítima, de causar dano à mesma.

Assim sendo, na responsabilidade civil subjetiva é imprescindível a prova da atuação culposa ou dolosa do agente para que surja o dever de indenizar.

Já na responsabilidade objetiva não se cogita a culpa ou dolo do agente, posto que esta se assenta na teoria do risco. Ou seja, na responsabilidade objetiva é irrelevante que o agente tenha atuado com culpa ou dolo. Basta que se comprove o dano e o nexo de causalidade entre o dano experimentado pela vítima e o ato do agente para que surja o dever de indenizar.

A teoria do risco, substrato da responsabilidade objetiva, estabelece que aquele que, através de sua atividade, cria um risco para a coletividade, na eventualidade de ocorrência de um dano, fica obrigado repará-lo, ainda que sua atividade e seu comportamento não tenham sido pontuados pela culpa. Como exemplo de responsabilidade objetiva podemos citar o caso de uma empresa que produz um lixo tóxico, capaz de poluir o meio ambiente. Se, porventura, esse lixo contaminar um rio, ainda que essa poluição não tenha sido provocada por um comportamento culposo da empresa, esta será obrigada a reparar o prejuízo causado ao meio ambiente.

Em conclusão, verificamos que no tocante à responsabilidade subjetiva e objetiva, o cerne da questão reside no fato de que na primeira, para que surja o dever de indenizar, faz-se necessário a prova da atuação culposa ou dolosa do agente, enquanto que na segunda, basta demonstrar a relação de causa e efeito entre o comportamento do agente e o dano experimentado pela vítima.
Pois bem, conforme dito acima, o artigo $\mathrm{n}^{\circ} 159$ do Código Civil Brasileiro expressa princípio geral de direito, informador de toda teoria da responsabilidade civil. Efetuando-se uma análise detalhada do mencionado artigo $\mathrm{n}^{\circ} 159$ verifica-se que ele engloba os pressupostos gerais da responsabilidade civil, a saber: ação ou omissão do agente, culpa do agente, relação de causalidade e o dano experimentado pela vítima.

No tocante à ação ou omissão do agente, há que se ressaltar que a responsabilidade do agente pode ser gerada por ato próprio, por ato de terceiro que esteja sob a responsabilidade do agente, e ainda de danos causados por coisas e animais que estejam sob a guarda deste.

Com relação à culpa do agente, já foram tecidas algumas considerações acerca do conceito de culpa e dolo. A relação de causalidade requer que se demonstre que o dano experimentado pela vítima resultou de um comportamento ou de uma atitude perpetrada pelo agente. Quanto ao dano, só se pode cogitar em responsabilidade civil a partir do momento em que houver um prejuízo. Em outras palavras, não há que se falar em dever de indenizar se não se verificar a ocorrência de um dano.

Por fim, cabe ressaltar que, de um modo geral, caberá à vítima provar a relação de causalidade entre a culpa do agente e o dano, ou seja, demonstrar que o prejuízo por ela experimentado derivou de uma conduta culposa do agente. No caso da responsabilidade objetiva, por sua vez, é preciso provar o nexo de causalidade entre o ato e o dano, hipótese em que não se cogita acerca da culpa do agente, como ocorre, por exemplo, na sistemática do Código de Defesa do Consumidor.

De outro lado, também se admite a presunção de culpa do agente, que é uma doutrina intermediária entre a culpa simples e a teoria do risco, das quais já falamos. Nestas circunstâncias, há inversão do ônus da prova, de modo que, ao invés da vítima comprovar a culpa do agente, é este que deve provar a sua não-culpa, ou seja, deve demonstrar que o evento danoso se deu por ato que escapou de seu controle, ou seja, deve demonstrar que o evento se deu por força maior, culpa exclusiva da vítima, etc.

\section{III - O dano provocado por animais}

\section{Análise das excludentes do artigo n⿳0 1527 do código civil}

$\mathrm{O}$ artigo ${ }^{\circ} 1.527$ do Código Civil estabelece que: "O dono, ou detentor, do animal ressarcirá o dano por este causado, se não provar: I. Que o guardava e vigiava com cuidado preciso. 11. Que o animal foi provocado por outro. 111. Que houve imprudência 


\section{do ofendido. IV. Que o fato resultou de caso fortuito, ou força maior."}

Em primeiro lugar, é mister salientar que o responsável pelo ressarcimento do dano causado pelo animal é o seu proprietário ou detentor, conforme se depreende da leitura do caput do mencionado artigo $\mathrm{n}^{\circ}$ 1.527. Note-se que o artigo menciona as expressões dono e detentor. No entanto, a idéia geral nele consubstanciada é a de que a responsabilidade é do guardião do animal, ou seja, é da pessoa que tem sobre o mesmo o poder de direção, devendo guardá-lo com o cuidado preciso para que ele não cause dano às pessoas

Ora, geralmente, nesta posição, temos a figura do dono. Entretanto, é possível que a condição de dono não se confunda com a de guarda, quando, por exemplo, o animal é cedido em comodato a outra pessoa. Nestas circunstâncias, este adquire a condição de guarda e, por essa razão, torna-se o responsável pelo dano que o animal causar a terceiro. O mesmo ocorre quando o animal foi furtado, pois nesta hipótese o seu dono não tem poder de direção sobre o mesmo, indispensável para exercer a vigilância capaz de evitar acidentes, razão pela qual o dono não poderá ser responsabilizado por eventuais danos causados pelo animal nestas circunstâncias.

Com relação à responsabilidade do dono, esta persiste ainda quando o animal encontrar-se sob a guarda de um empregado ou preposto, a teor do que dispõe o artigo $\mathrm{n}^{\circ} 1.521$, inciso III, do Código Civil Brasileiro. Este dispositivo preceitua que o patrão será responsável pela reparação dos danos causados por seus empregados, sendo típico exemplo de responsabilidade civil por ato ou fato de terceiro.

No tocante ao regime da responsabilidade, este preceito estabelece uma exceção à regra geral da responsabilidade civil (artigo ${ }^{\circ} 159$ do Código Civil), segundo a qual cumpre à vítima do dano demonstrar a culpa do agente causador do prejuízo, ou seja, que o prejuízo por ela experimentado decorre diretamente de uma conduta culposa do agente. Entretanto, embora não se enquadre nesse regime de responsabilidade, também não pode ser relacionado entre os casos de responsabilidade objetiva.

Dessa forma, conforme já explicitado no item precedente, no caso do artigo $\mathrm{n}^{\circ} 1.527$ do Código, há uma presunção de responsabilidade. Em outras palavras significa dizer que o dono, ou detentor, do animal somente se exonera do dever de indenizar se provar a ocorrência de uma das excludentes consignadas no referido dispositivo legal. Portanto, há uma inversão do ônus da prova, que deixa de incumbir à vítima e passa ao dono ou detentor do animal.
Assim sendo, para que surja o dever de indenizar do dono ou detentor do animal, no curso de uma ação de judicial, a vítima deverá provar apenas que sofreu o dano, que esse dano foi provocado por um animal e que este pertence ao réu. $\mathrm{O}$ dono ou detentor do animal é que deverá provar a sua não culpa, ou seja, deverá provar uma das excludentes do artigo ${ }^{\circ} 1.527$ do Código Civil.

Após essas considerações iniciais, passemos, en-

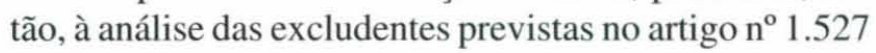
do Código Civil.

Com efeito, a presunção de culpa consubstanciada no referido artigo somente poderá ser ilidida pela prova, a ser produzida pelo dono ou detentor do animal (em linhas gerais, o guarda): I. de que guardava e vigiava o animal com cuidado preciso; II. de que o animal foi provocado por outro; III. de que houve imprudência do ofendido; IV. de que o fato resultou de caso fortuito ou força maior.

Com relação à primeira excludente, o legislador abriu a possibilidade de o guarda exonerar-se do dever de indenizar se provar sua vigilância e diligência. Aqui surge a questão de saber qual o grau de vigilância e diligência. A lei não se contenta com o cuidado e diligência de um homem normal. A simples demonstração do dono ou detentor do animal de que seu procedimento foi idêntico ao do homem mediano não o isenta de responsabilidade.

Isto ocorre porque, segundo explica o Professor Silvio Rodrigues (RODRIGUES, 1989), o legislador utilizou o adjetivo preciso, qualificando o substantivo cuidado, que se refere à diligência reclamada do guarda. $\mathrm{O}$ cuidado deverá ser aferido de acordo com o caso concreto, levando-se em consideração o animal em questão; se for muito perigoso, a vigilância deverá ser rigorosa Em outras palavras, significa dizer que o proprietário ou detentor somente se libertará da responsabilidade pelo dano provocado pelo animal se provar que exerceu a vigilância e diligência precisas para evitar o evento danoso, e que, apesar de seu cuidado, houve um fato extenso imprevisível e irresistível.

É claro que a expressão cuidado preciso é muito genérica, devendo ser aferida no caso concreto. Não se trata, portanto, de um conceito fechado. $\mathrm{O}$ magistrado deverá verificar se no caso em exame houve ou não o cuidado adequado para o animal envolvido na questão. A presunção de culpa será ilidida pela comprovação de que não houve infração ao dever de vigilância. De qualquer forma, a matéria reservaria ao prudente arbítrio do juiz.

Essa excludente vem se tornando letra morta, exatamente pela admissão da idéia de que "se houve dano é porque o dono do animal não o vigiou com o cuidado pre- 
TROPARDI, N. C. O. A posse de animais e a responsabilidade civil. / Animal ownership and civil responsibility. Rev. educ. contin. CRMV-SP/Continuous Education Journal CRMV-SP, São Paulo, volume 2, fascículo 3, p. 077 - 083, 1999.

ciso (GONÇALVES, 1986)". Nessa linha de raciocínio já se assentou a jurisprudência pátria, conforme pode-se observar no julgado publicado na Revista dos Tribunais n.641, pp.182, onde se lê que "o cuidado preciso referido no inciso I do artigo ${ }^{\circ} 1.527$ do Código Civil não é o cuidado normal, mas o necessário para que não ocorra o dano. Se há dano é porque o dono do animal não o vigiou com o cuidado preciso, tornando inócuo e supérfluo o aludido inciso, sendo despicienda a oitiva de testemunhas para demonstrar o mencionado cuidado."

Com relação à segunda excludente - $o$ animal foi provocado por outro - se o prejuízo decorrer do próprio impulso do animal, seu dono ou detentor será responsável. Entretanto, se o animal agiu provocado por outro animal, seu dono ou detentor não terá nenhuma responsabilidade. Ou seja, o dono ou detentor exonerar-se-á do dever de indenizar o prejuízo causado pelo animal que estava sob sua vigilância se demonstrar que houve provocação imprevisível ou inevitável de outro bicho, de forma que não lhe foi possível evitar o dano. Nesta hipótese a responsabilidade será do dono ou detentor do animal provocador. Se porventura não for possível encontrar o animal provocador, o quantum dos prejuízos deverá ser distribuído entre os dois proprietários, uma vez que não se pode permitir que a vítima não seja reparada pelos danos experimentados.

A terceira excludente - o ofendido agiu imprudentemente - diz respeito à hipótese de a vítima ter se aproximado de um animal sem o devido cuidado, mesmo sabendo que ele era perigoso. É o caso da vítima que, por exemplo, aproxima-se de um cachorro bravo, com histórico de efetuar mordidas nas pessoas, e coloca sua mão dentro da jaula do bicho. Ou então a vítima provoca um cachorro feroz e é atacada por ele, segundo acórdão publicado na RT $257 / 485$. Ora, se a vítima deliberadamente provocou o animal, não há que se falar em responsabilidade de seu dono. E claro não se enquadra nesta excludente a mera negligência, consubstanciaria, por exemplo, na hipótese da vítima que desfere um pontapé no animal na tentativa de livrar-se de seu ataque.

Com relação a esta excludente há ainda que se mencionar que se a imprudência da vítima e a negligência do guarda forem, simultaneamente, causas do ato danoso, haverá culpa concorrente da vítima, hipótese em que a reparação do prejuízo será apenas parcial.

A quarta e última excludente - o fato resultou de caso fortuito ou força maior - diz respeito a acontecimentos imprevisíveis e inevitáveis. Trata-se de excludente genérica, aplicável em muitos casos de responsabilidade civil. O caso fortuito ou força maior pode ser definido, em linhas gerais, como o acontecimento imprevisível, contra o qual não há defesa. É o caso, por exemplo, de um terremoto, cuja previsão não era possível, que causou verdadeira catástrofe.

Em conclusão, tendo por base o fato de que as excludentes previstas nos incisos I e II só servirão para ilidir a responsabilidade se provocadas por fato imprevisível e inevitável, podemos afirmar que a tendência atual é a de somente permitir a exoneração do dono ou detentor do animal em casos de culpa da vítima, força maior ou caso fortuito.

Finalmente, há ainda algumas considerações que precisam ser tecidas a respeito do artigo $\mathrm{n}^{\circ} 1.527$ do Código Civil. Em primeiro lugar, este artigo aplica-se também a animais não perigosos, o que significa dizer que a distinção perigoso e não perigoso não tem qualquer importância. Um animal manso, quando acuado, pode atacar, ferir uma pessoa. De qualquer forma, cada caso será analisado segundo suas particularidades, sendo que não se pode concluir em hipótese alguma, que o dano provocado por um animal pacato não enseja a responsabilidade civil de seu dono ou detentor. É claro que se o animal for perigoso, feroz, o dever de vigilância e diligência de seu guarda deverá ser muito mais rigoroso, podendo-se afirmar que será mais difícil que o mesmo consiga exonerar-se do dever de indenizar.

Em segundo lugar, se o animal que provocou o dano não estava devidamente vacinado, este fato constituiu um agravante à responsabilidade de seu dono ou detentor. Ou seja, este fato servirá para reforçar a presunção de culpa do dono ou detentor do animal em questão.

Por fim, há que se ressaltar que o artigo $\mathrm{n}^{\circ} 1.527$ do Código Civil não se aplica aos animais silvestres, ou seja, aos animais selvagens, que não vivem em ambiente social. Assim, por exemplo, se há uma festa numa fazenda e um dos convidados é mordido por uma cobra, não há que se falar em responsabilidade do dono da fazenda pelo dano experimentado pela vítima.

\section{IV - Breves considerações sobre o processo judicial para reparação dos danos provocados por animais}

Em caso de danos provocados por animais, o lesado poderá ingressar com ação judicial objetivando a reparação de todos os danos por ele experimentado. A extensão do pedido desta ação dependerá, obviamente, dos danos provocados à vítima. Assim sendo, passaremos à análise dos vários tipos de danos que o ataque de um animal poderá provocar.

Em primeiro lugar, há o dano patrimonial, que pode ser definido como a lesão que afeta o patrimônio da víti- 
ma, consistente na perda ou diminuição dos bens materiais que lhe pertencem e sendo suscetível de avaliação pecuniária. Assim, se um cachorro mordeu uma pessoa e causou um ferimento que obrigou-a a valerse de serviços médicos e hospitalares, provocou um dano patrimonial à vítima, dano este que deverá ser indenizado.

Da mesma forma ocorre quando o ataque de um animal provocar a destruição, por exemplo, de várias plantas de uma pessoa. Ora, se essas plantas tem um valor econômico, é óbvio que o prejuízo produzido deverá ser devidamente reparado.

Há também o dano moral, entendido como a lesão a interesses não patrimoniais da vítima. É o sofrimento de ordem psíquica, é a dor n'alma da vítima. Se o ataque do animal provocou ferimentos na vítima, além do dano patrimonial, compreendido como o ressarcimento de todas as despesas relativas ao seu restabelecimento, haverá também o dano moral, que deverá ser devidamente reparado. No exemplo acima, o dano moral é identificado pelo sofrimento da vítima, sofrimento este decorrente do ataque por ela experimentado.

Por fim, há que se falar também do dano estético, definido como "qualquer modificação duradoura ou permanente na aparência externa de uma pessoa, modificação esta que lhe acarreta um 'enfeamento' e lhe causa humilhações e desgostos, dando origem portanto a uma dor moral" (ANCONA LOPES, 1999).

Assim sendo, voltando ao exemplo do animal que atacou uma pessoa e provocou-lhe diversos ferimentos, se estes ferimentos resultaram, por exemplo, numa cicatriz em seu rosto, além do ressarcimento dos danos patrimoniais e morais a vítima poderá pleitear uma outra verba, destinada a reparar o dano estético. Neste exemplo o dano estético está consubstanciado nesta cicatriz, que provocou um 'enfeamento' da vítima.

Aliás, pertinente observar que o dano estético para ser indenizável, não precisa estar localizado numa parte do corpo da vítima visível por todos. Ou seja, tomando por base o exemplo anterior, não é preciso que a cicatriz seja no rosto, visível por qualquer pessoa a todo momento. Mesmo que a referida cicatriz esteja localizada, por exemplo, na barriga da pessoa, configura dano estético, devendo, portanto, ser indenizado.

Com relação ao valor da verba indenizatória destinada a reparar o dano patrimonial, esta será apurada mediante o cálculo das despesas efetuadas pela vítima com o tratamento médico e hospitalar de seus ferimentos. Aqui entra todo tipo de despesa, desde os remédios receitados à vítima, até os gastos com médicos, hospitais, cirurgião plástico, etc.
No tocante à fixação dos valores destinados a reparar os danos morais e estéticos, pode-se afirmar que esta é uma questão por demais árida, que ainda não encontrou tratamento uníssono em nosso ordenamento jurídico, uma vez que não há uma lei que disponha sobre o assunto, nem tampouco construções doutrinárias capazes de dirimir todas as dúvidas que pairam nesta matéria.

De qualquer forma, tais valores acabam sendo fixados pelo juiz segundo seu prudente arbítrio, conforme preceitua o artigo $\mathrm{n}^{\circ} 1.553$ do Código Civil. O que normalmente se faz é indicar alguns critérios que poderão ser levados em consideração pelo juiz na fixação do quantum indenizatório, embora ele não esteja obrigado a adotar tais critérios.

O que deve ficar claro é que a vítima diante de um ataque de um animal poderá pleitear a reparação de todos os danos que experimentou, sendo que haverá cumulação de todas essas verbas indenizatórias. A Súmula 37 do STJ dirimiu quaisquer dúvidas acerca da possibilidade de cumulação das indenizações por dano material e moral, na medida que estabelece que "São cumulacíveis as indenizações por dano material e dano moral oriundos do mesmo fato". Com relação à cumulação das indenizações por dano moral e por dano estético, esta ainda não é pacífica na jurisprudência brasileira, sendo que há forte tendência em se admitir referida cumulação.

Como exemplo desta conclusão podemos citar o seguinte acórdão: INDENIZAÇÃO - Ataque por cães bravios - Danos físicos e morais - Culpa in vigilando caracterizada - Reparação devida. Demonstrada a culpa in vigilando daqueles que mantêm sob sua guarda cães ferozes, os danos físicos e morais causados à vítima, que em nada concorreu para o evento, devem ser ressarcidos, de modo mais amplo possível, pelo proprietário ou por quem tem a guarda dos animais" (LOPEZ, I999).

Por outro lado, se houver morte da vítima, além do ressarcimento do dano moral, aplicar-se-á o artigo no 1537 do Código Civil que prescreve: "A indenização, no caso de homicídio, consiste: I- No pagamento das despesas.com o tratamento da vítima, seu funeral e o luto da família. II - Na prestação de alimentos às pessoas a quem o defunto os devia". Assim, se a vítima fatal do ataque de um cão for um pai de família, além da indenização pelo dano moral, consubstanciado na perda de um ente querido, sua esposa e seus filhos poderão pleitear alimentos do dono ou detentor do animal, uma vez que viviam sob a dependência da vítima.

A pensão a ser paga à viúva do falecido deve ter como marco inicial o evento da morte e prevalecerá pelo período de vida provável da vítima que, segundo a juris- 
TROPARDI, N. C. O. A posse de animais e a responsabilidade civil. / Animal ownership and civil responsibility. Rev. educ. contin. CRMV-SP / Continuous Education Journal CRMV-SP, São Paulo, volume 2, fascículo 3, p. 077 - 083, 1999.

prudência pátria, é de 65 (sessenta e cinco) anos. O pagamento desta pensão cessará, contudo, quando a viúva convolar novas núpcias.

No tocante à pensão a ser paga aos filhos menores da vítima, esta deverá ser paga até que os mesmos completem 25 anos, quando, presumivelmente, se casariam e cessaria o auxílio paterno ou materno. No entanto, se antes desse termo final um dos beneficiários falecer, a sua parte acrescerá à dos sobreviventes.

Da mesma forma pode-se falar em pensão mensal no caso de morte de filho menor, ainda que não exerça trabalho remunerado, segundo preceitua a Súmula 491 do $\mathrm{STF}^{\prime}$ (É indenizável o acidente que cause morte de filho menor, ainda que não exerça trabalho remunerado). Nesta hipótese, a pensão deverá ser paga até que a vítima menor alcance 25 anos, quando, presumivelmente, se casaria, deixando de prestar ajuda aos pais.

Por outro lado, se do ataque do animal resulta na vítima lesões que provoquem a redução de sua capacidade laborativa, ou seja, que a incapacitem para o exercício de um trabalho, deverá receber, além de todas as outras verbas indenizatórias, também uma pensão vitalícia, ou seja, sem qualquer limitação temporal. É o que determina o artigo $\mathrm{n}^{\circ} 1.539$ do Código Civil, a saber: "Se a ofensa resultar defeito, pelo qual o ofendido não possa exercer o seu ofício ou profissão, ou se lhe diminua o valor do trabalho, a indenização, além das despesas do tratamento e lucros cessantes até o fim da convalescença, incluirá uma pensão correspondente à importância do trabalho, para que se inabilitou, ou da depreciação que ele sofreu".

A pensão será vitalícia porque se a vítima, em razão do infortúnio, é hoje incapaz, também o será aos 65 anos de idade. Em outras palavras significa dizer que se hoje não tem condições de exercer uma atividade produtiva e remunerada, muito menos as terá quando estiver com uma idade mais avançada, razão pela qual não há que se falar em limite temporal para este tipo de pensão.

Com relação às garantias da indenização, o artigo ${ }^{\circ} 602$ do Código de Processo Civil determina que o devedor constitua um capital que assegure o cumprimento da obrigação. Esse capital deverá ser composto por imóveis ou títulos da dívida pública, sendo que tais bens serão inalienáveis e impenhoráveis.

$\mathrm{O}$ fato de tais bens ficarem vinculados ao pagamento de prestações futuras não significa que deixaram de pertencer ao devedor (causador do dano), na medida em que enquanto este estiver honrando o pagamento das prestações, a renda destes bens continuará a pertencer ao devedor (causador do dano). Se, porventura houver inadimplemento, a renda desses bens será transferida ao beneficiário da pensão. Caso esse capital não produza renda, será transformado em uma soma em dinheiro equivalente ao total da pensão devida.

$\mathrm{O}$ que se quer com isso dizer é que tais bens não se transmitem ao credor (vítima do dano), mas continuam na propriedade do devedor (causador do plano). Apenas sofrem limitações na sua disponibilidade. Tal indisponibilidade deve ser averbada no registro desses bens, a fim de evitar a menor probabilidade de venda por parte do devedor.

A jurisprudência brasileira entende como mais recomendável, e com maior garantia, a constituição desse capital, por intermédio de depósito bancário e em caderneta de poupança de certa quantia, a render juros e correção monetária, bloqueadas as retiradas, salvo as pensões do credor, sendo aconselhável que seja depositado uma quantia capaz de ensejar razoável grau de segurança, de sorte a evitar que as retiradas não o consumam.

Por fim, vale ressaltar que ambas as hipóteses não são satisfatórias, posto que, no caso dos imóveis ou títulos da dívida pública, a sua transformação imediata em renda requer providências burocráticas, o que acaba por tornar dificultosa a liquidez dos mesmos. No caso da constituição de capital mediante depósito em conta corrente bancária, verifica-se que a modificação constante de nossa moeda tem pulverizado esses capitais constituídos. Portanto, nunca há certeza de que o capital será devidamente recomposto, nem tampouco de que a reparação da vítima estará assegurada.

Diante dessa conclusão, afirma-se que a satisfação das prestações mensais vincendas estaria melhor assegurada com a inclusão do autor em folha de pagamento da empresa onde o devedor exerce sua atividade profissional. Caso isso não seja possível, em razão das circunstâncias do caso concreto, resta a hipótese da caução fidejussória, com observação de que ela não pode ser prestada pelo próprio devedor, pois, em se tratando de garantia pessoal, não teria sentido o devedor ser garante de si mesmo.

\section{V - Dos aspectos penais}

Nesta parte final, serão feitas algumas considerações com relação ao aspecto penal da presente questão. Com efeito, a omissão na guarda de animais é crime previsto no artigo 31 da Lei das Contravenções Penais (Decreto-lei $n^{\circ} 3.688$ de 3.10.41). a saber: "Deixar em liberdade, confiar à guarda de pessoa inexperiente, 
ou não quardar com a devida cautela animal perigoso: Pena - prisão simples, de 10 (dez) dias a 2 (dois) meses, ou multa. Parágrafo único. Incorre na mesma pena quem: a) na via pública, abandonar animal de tiro, carga ou corrida, ou confiar a pessoa inexperiente; b) excita ou irrita animal, expondo a perigo a segurança alheia; $c$ ) conduz animal, na via pública, pondo em perigo a segurança alheia."

Contudo, o referido artigo $\mathrm{n}^{\circ} 31$ terá aplicação apenas nos casos em que os danos provocados por animais não resultarem em lesões corporais à vítima, nem tampouco em morte da mesma, posto que, conforme citado acima, pune apenas a omissão na guarda de animais. Se o evento danoso resultar em lesões à vítima, ou mesmo em sua morte, deverão ser observados os dispositivos do Código Penal referentes a estes crimes.

Assim, se um animal atacar uma pessoa, sobrevindo ferimentos à vítima, verifica-se a ocorrência do crime de lesão corporal, sendo que o dono ou detentor do animal deverá responder por este crime, nos exatos termos do artigo $\mathrm{n}^{\circ} 129$ do Código Penal. Se houver morte da vítima, responderá por homicídio culposo, a teor do que dispõe os parágrafos $3^{\circ}, 4^{\circ}$ e $5^{\circ}$, artigo $\mathrm{n}^{\circ} 121$ do mesmo Código Penal. Vale ressaltar, contudo, que em ambos os casos as penas cominadas são mais severas que as previstas no citado artigo $\mathrm{n}^{\circ} 31$ da Lei das Contravenções Penais.

\section{SUMMARY}

The objective of this article is to analyse the civil resposibilities of the animal owner due to any damage it may have caused. General aspects dealt with in the Brazilian law are considered. A detailed analysis of the article number 1,527 of the Código Civil (which establishes the responsibility of the owner of the animal) is performed, besides a brief discussion on judicial actions that may carried out by the victims, indemnity and penal issues.

Key words: animal ownership, civil responsibility, damage caused by animals.

\section{BIBLIOGRAFIA DE APOIO}

1 - ANCONA LOPEZ, T. O dano estético. $2^{\mathrm{a}}$ ed., São Paulo: Revista dos Tribunais, 1999, p. 38.

2 - BITTAR, C. A. Reparação civil por danos morais. $3^{\mathrm{a}}$ ed., São Paulo: Revista dos Tribunais, 1998, p. 232.

3 - DINIZ, M. H. Curso de Direito Civil - responsabilidade civil, São Paulo: Saraiva, 1984, p. 358.

4 - GONÇALVES, C. R. Responsabilidade civil, $3^{\text {a }}$ ed., São Paulo: Saraiva, 1986, p. 182.
5 - RODRIGUES, S. Responsabilidade civil. 16 a ed., São Paulo: Saraiva, 1989, p. 123.

6 - SEVERO, S. Os danos extrapatrimoniais. São Paulo: Saraiva, 1996, p. 121.

7 - STOCO, R. Responsabilidade civil e sua interpretação jurisprudencial. $4^{\mathrm{a}}$ ed., São Paulo: Revista dos Tribunais, 1999, p. 494. 